\title{
Could Managers Consider Waiting Times as Something Positive?
}

\author{
Gilda Hernandez-Maskivker \\ Bussiness Department \\ Rovira I Virgili Universty \\ Reus, Tarragona, Spain \\ gildamaria.hernandez@urv.cat
}

\author{
Gerard Ryan \\ Bussiness Department \\ Rovira I Virgili University \\ Reus, Tarragona, Spain \\ gerard.ryan@urv.cat
}

\begin{abstract}
Normally managers consider waiting times as something negative they must minimize or delete. The objective of this paper is to explore how managers perceive waiting times and in which sense the wait can be considered as something positive. This qualitative paper seeks to demonstrate that waiting times can be considered not only as a problem, but requires an analysis from other perspectives. Six in-depth interviews were carried out in order to explore manager's perception of waiting times in tourism and leisure contexts.
\end{abstract}

Keywords-waiting times; service's managers; tourism and leisure services

\section{INTRODUCTION}

Research suggests that efficiency and speed in services are some of the features most requested by consumers [1]. Today, customers want instantly what they purchase, without delays. They don't want to waste any time waiting or queuing [2]. Time is a scarce good valued in the same way as money [3], [4] Companies are aware that to increase consumer satisfaction and to increase their profits, they have to minimize waiting times [5], [6], [7]. Customers who are made to wait may leave the queue [8], [9] or may wait but not return on future occasions [10], [11], [12]. Waiting may affect repeat-purchase behaviour [13], [14] and it may have a negative effect on the overall evaluation of the service [15], [16], [17], [18], [7], [19].

Waiting times are a daily problem for several companies [20], [8] and managers are constantly searching for new alternatives to manage them. Until recently, research on the subject has focused on the negative aspects of waiting; still very few studies highlight the potentially positive aspects of waiting. This paper is original in exploring manager's perception about a possible positive view of waiting times. A pilot study involving six interviews was undertaken. After this brief introduction, the second section reviews waiting times and queues in tourism and leisure services. The third section then explains the methods used in conducting this pilot study. Next, the findings of the exploratory study are presented. Finally, conclusions and future lines of research are suggested.

\section{THEORETICAL FRAMEWORK OF WAITING}

Tourist and leisure services are prone to long and frustrating periods of waiting [21]. Customers wait at airports, museums, theaters, sport events, concerts, restaurants, landmarks or theme parks. It is a ubiquitous phenomenon and customers consider time waiting as an inevitable part of the service experience [22], [21], [23].

Companies basically have two ways to manage waiting times. On the one hand they can reduce the real waiting time, for example by extending the opening hours, hiring more employees or implementing new technologies as machines which sell products or assist customers [6], [14], [11]. These operational solutions may reduce the real waiting time but can also bring disadvantages. For instance, they can include large investments of money or it can be difficult for consumers to adapt to new technologies [1]. On the other side managers may attempt to reduce the perceived waiting time [24], [25], [17], [14]. For instance, managers may minimize the perceived waiting time providing pleasant waiting environments [26], [27].

Tourist and leisure services have adopted strategies used in other services to manage waiting times; focusing their efforts on how to reduce or eliminate this problem. For instance, theme parks or airlines use systems where customers can pay extra to avoid queues [28], [29], [30] museums and galleries give the opportunity to buy tickets before arriving at the site and restaurants let their clients wait for dinner in a pleasant bar at the entrance of the restaurant [13]. All these efforts are based on the premise that waiting is negative and companies have to minimize it. However, eliminating waiting times might be not the best solution as waiting may not always be negative. Some studies focus on this and suggest viewing waiting from a positive perspective [31], [32], [33], [34]. For instance, it has been suggested that a certain amount of waiting may enhance the tourist experience if waiting time is filled with activities that increase the fun factor [35], [36]. Further studies propose that tourists come to expect and even accept a certain amount of waiting [37], so they're not really that bothered if they have to wait [38]. In addition, in certain leisure contexts, such as queuing for sporting events or queuing to see a new movie, consumers may actually enjoy the wait because of the social atmosphere created in the queue [39], [40], [41].

\section{METHODOLOGY AND FINDINGS}

To explore the perception of service managers about waiting times, a qualitative approach was deemed appropriate. Since it is an unexplored area, in depth interviews were judged as the appropriate data collection method. In particular, semi- 
structured interviews, an hour in length, were conducted and transcribed, with three managers of theme parks and three managers of nightclubs located in Spain. The six cases were not extreme cases, but were theoretically sampled based on their current activities and their years of experience managing tourist and leisure services.

The interviews were framed by a number of core questions areas: how they manage waiting times; how they consider waiting times in tourist and leisure services. Participants, however, were free to raise and explore anything they considered salient to their experiences. Questions were formulated in an open-ended manner to elicit their perspectives on the issues explored. Nvivo software was utilized to code and analyze the qualitative data.

In general, waiting is considered as an inconvenience. As research on marketing and operations management, all respondents interpret waiting as a problem they face daily. For instance, theme parks as sets of rides, spectacles and leisure mechanisms are intended to entertainment and spark the imagination of customers, allowing people to escape their daily routine [9]. However, waiting is often a problematic issue that can influence the tourist experience and that can appear as one of the principal motives for complaints. All respondents agree waiting has negative effects on customer satisfaction and service performance [14], [16], [42], [43], [15]. Waiting reduces perceived service quality, waiting can be a barrier for new clients or also waiting can be a barrier for new visitors. The following two quotes expand on this subject:

"When you do market research on theme parks, one of the negatives, perhaps the most important, are queues". (Interviewee 2)

Managers also explain how they face waiting times and the different tools they use to reduce real or perceive waiting times. The following quotes expand on some of these strategies:

"We don't entertain people queuing but we try to delimit a down time in the aquatic rides to make queues move faster" (Interviewee 1)

"In the park... the focus is on making queues less boring....In fact there are pre-shows before the shows to make queues less boring." (Interviewee 2)

In spite of all these efforts to reduce real and perceived waiting times, they are still present in tourist and leisure contexts. As the literature suggests, sometimes waiting times are inevitable in service contexts [36], [44], [45], [46]. For example, this happens when demand exceeds service's capacity, as the following quote explain:

"It is a point where demand is higher than your capacity. For instance, there is a ride that allows 1,500 people ride on it in one hour, with all trains running and all employees working. If more than 1,500 people come in the same hour, so you have the phenomenon of queues and you can't do anything about it." (Interviewee 3)

What is surprising is that, in some circumstances, customers may assume the inevitability of waiting. In some situations, consumers can interpret delays and queues as something normal that can be considered as part of the experience [21],
[23], [37]. For instance, one of the interviewees said people may assume that there will be queues when they are familiar with the service, when they are repeated clients:

"There were experienced people who knew when they had to visit the park, when there were fewer queues, and in any case they were aware that they would find queues and they had absolutely assumed it. They did not give much importance to the issue of queues.... When we did market research, a focus group in Barcelona for example, non-visitors said queues generate a negative reaction. However, people who have visited the theme park, they quickly put their arguments in the background and queues did not affect their decisions. They were happy, excited, and they loved the park. They were regulars visitors ...." (Interviewee 2)

This suggests that waiting is not always a serious problem. As we can see in the next quote, managers are not always so concerned about waiting times and they also assume the inevitability of delays:

"The queue is not a problem. It's something that goes with the place ... If the nightclub opens from 12 to $5 \mathrm{am}$ and there is a half-an-hour queue, at the end it is not so much. And this doesn't happen all the time." (Interviewee 4)

In addition, taking into account what happens at theme parks, customer satisfaction may not depend entirely on the public attendance or long waiting periods. Except on specific moments and days of the year, waiting may not influence have such a significant effect on customer satisfaction or company performance.

"There was a curve where satisfaction did not depend on public attendance (up to 15,000 visitors). From more than 15,000 visitors, satisfaction decrease. But it wasn't a dramatically decline. Maybe a big fall happened in those specific days, even days when doors were closed because it was impossible to operate." (Interviewee 2)

Ironically, as the following quotes explain, the months with the most attendance (when there usually are longer waiting times) are the months where there are higher rates of customer satisfaction at theme parks.

"The month of greatest satisfaction of the park, historically, is always July. And July is the second busiest month. That means that when the park was operating at a hundred percent in terms of employees, then the park was able to satisfy the expectations of customers, and the customer satisfaction was high...Satisfaction was worse in low season than in high season. Therefore, queues did not affect dramatically on customer satisfaction, except on specific days." (Interviewee 2)

As we can see, waiting may not have such a negative effect as is generally believed in the waiting literature. Based on data provided by the manager's interviews, the following section suggests a more positive interpretation of waiting times: waiting times as a source of revenues.

\section{A. Waiting Times as a Source of Revenues}

In light of the persistence of waiting in theme parks and the ongoing concern of companies to adapt their products and services to the inconstant demand and tourism market changes 
[47] fast lines systems appeared as a potential solution for reducing waiting times [48], [49], [44], [45]. Hence, fast line, express queue or VIP systems were introduced, whereby consumers could pay extra to join a priority queue separated from regular customers. Over time these systems have become very common in the tourism industry [50], [51] and particularly in theme parks. Universal Studios, Six Flags, Port Aventura, Knott's Berry Farm and Legoland are some examples of the theme parks that offer an express pass or flash pass that allow guests to bypass regular lines at several rides.

Fast lines reduce customer dissatisfaction with lines [44]. Interestingly, this may also apply in the case of regular consumers, as priority lines also help to reduce the length regular queues, thus reducing waiting times for all [4]. Also, fast lanes help to reduce congestion at theme parks [49] and facilitate improved queue management and customer's flows around the premises [44].

In adittion, fast lines contribute to profitability as an important source of revenue for firms [44], [45]. The growing demand for express passes at theme parks has made this product a significant source of revenues for companies [44], [45]. Indeed, companies can adjust the price of the express pass according to their needs [44] as long as it provokes a sufficient difference between the priority and the regular line and in turn this should provide benefits to cover the extra staff needed for the extra line [4]. When companies offer the possibility of purchasing a fast line they are creating two different groups of customers: high priority groups and low priority groups according to required waiting time and the price customers are willing to pay [4]. Research suggests there are customers who are highly sensitive to waiting times and are willing to pay to avoid or reduce lines.

The managers interviewed coincide with the literature explaining express pass allow achieve those two objectives. On one hand, it solves the problem of queues for a market segment that is willing to pay for avoids regular queues. On the other hand, and this is important for this proposition, companies get extra revenues from the sale of express passes. More waiting times are inevitable related with more sales of express passes.

“..you kill two birds with one stone, first you satisfy your client... and moreover you get income. Whoever wants to pay is satisfactory for all to pay. Then, you reduce the impact of the queue for a particular segment, which you provide satisfaction and this generates an income."(Interviewee 2)

In fact, when we asked the managers if they would eliminate completely the queues, one of them has responded the following:

"I wouldn't eliminate completely the queues. On one side the fact that there are queues means that the express pass exists and companies earn a lot of money with the express pass. People pay a lot to avoid the queues." (Interviewee 5)

From this, a positive view of waiting times is possible if we consider them as a source of revenues. More waiting times can lead to more sales of express passes. However, it shouldn't be forgotten the original goal of express systems is to improve customer satisfaction and not to get direct incomes from the sale of them.

\section{CONCLUSIONS}

The main objective of this pilot study was to explore the perception of managers about waiting times and the possibility to consider them as something positive in service contexts. The findings demonstrate waiting is not always necessarily negative. Although the interviewees considered in general waiting times as an inconvenient for the proper development of services, they also have detected certain specific situations where waiting may be considered as something 'positive'. For instance, the presence of waiting times at theme parks ensure companies can sell the express pass. Despite not being the original goal of the express pass system, sales of express passes produce important revenues for companies. In addition, offering this service to a segment of the market that is willing to pay creates customer satisfaction. Finally, rather than eliminating regular or priority queues, in certain situations we should encourage them.

A relevant contribution of this type of study is that it can provide valuable information that can be used by companies and marketers. Managers of leisure and tourist companies can obtain new perspectives about waiting times and how to improve inevitable delays. These new interpretations of waiting can affect their decision-making regarding customer experience. It is clear the need to consider the client experience from a more holistic point of view.

The main limitation of this work is determined by its very nature as an exploratory study, which does not allow the findings to be generalized. With regard to manager perception, it was evident that they interpret waiting propositions from their personal experiences in services. Future research may explore other positive considerations on waiting times and factors that can affect customer perceptions.

\section{REFERENCES}

[1] T. Swartz, D. Iacobucci, "Handbook of services marketing and management", Sage, 2000.

[2] W. Fung, "A study of queue: consumers'purchase intention tradeoff between perceived product quality and perceived sacrifice", Marketing Option, Working paper, 2006.

[3] F. Leclerc, B. Schmitt, L. Dube, "Waiting time and decision making: Is time like money?", Journal of Consumer Research, , pp. 110-119, 1995.

[4] H. Friedman, L. Friedman, "Reducing the "wait" in waiting-line systems: Waiting line segmentation", Business horizons, vol. 40, no. 4, pp. 54-58, 1997.

[5] M. Kostecki, "Waiting lines as a marketing issue", European management journal, vol. 14, no. 3, pp. 295-303, 1996.

[6] R. Yan, S. Lotz, "The waiting game: The role of predicted value, wait disconfirmation, and providers' actions in consumers' service evaluations", Advances in consumer research, vol. 33, pp. 412-418, 2006

[7] M. Hui, D. Tse, "What to tell consumers in waits of different lengths: An integrative model of service evaluation", Journal of Marketing, vol. 60, no. 2, pp. 81-90, 1996.

[8] R. Zhou, D. Soman, "Looking back: Exploring the psychology of queuing and the effect of the number of people behind", Journal of Consumer Research, vol. 29, no. 4, pp. 517-530, 2003.

[9] Z. Carmon, J. Shanthikumar, T. Carmon, "A psychological perspective on service segmentation models: The significance of accounting for consumers' perceptions of waiting and service", Management Science, vol. 41, no. 11, pp. 1806-1815, 1995. 
[10] F. Bielen, N. Demoulin, "Waiting time influence on the satisfactionloyalty relationship in services", Managing Service Quality, vol. 17, no. 2, pp. 174-193, 2007.

[11] M. Davis, T. Vollmann, "A framework for relating waiting time and customer satisfaction in a service operation", Journal of Services Marketing, vol. 4, no. 1, pp. 61-69, 1990.

[12] G. McDougall, T. Levesque, "Waiting for service: the effectiveness of recovery strategies", International Journal of Contemporary Hospitality Management, vol. 11, no. 1, pp. 6-15, 1999.

[13] L. Dube, L. Renaghan, J. Miller, "Measuring customer satisfaction for strategic management", Cornell Hospitality Quarterly, vol. 35, no.1, 3947, 1994.

[14] M. Davis, J. Heineke, "Understanding the roles of the customer and the operation for better queue management", International Journal of Operations \& Production Management, vol. 14, no. 5, pp. 21-34, 1994.

[15] M. Bitner, B. Booms, M. Tetreault, "The service encounter - diagnosing favorable and unfavorable incidents", Journal of Marketing, vol. 54, no.1, pp. 71-84, 1990.

[16] W. Lee, C. U. Lambert, "The effect of waiting time and affective reactions on customers' evaluation of service quality in a cafetería", Journal of Foodservice Business Research, vol. 8, no. 2, pp. 19-37, 2006.

[17] A. Pruyn, A. Smidts, "Effects of waiting on the satisfaction with the service: Beyond objective time measures", International journal of research in marketing, vol. 15, no. 4, pp. 321-334, 1998.

[18] S. Taylor, "Waiting for service: The relationship between delays and evaluations of service", Journal of Marketing;Journal of Marketing, vol. 58, no. 2, pp. 56-69, 1994.

[19] J. Hornik, "Situational effects on the consumption of time", The Journal of Marketing, , pp. 44-55, 1982.

[20] S. Milgram, H. J., R. Toledo, J. Wackenhut, "Response to intrusion into waiting lines", Journal of Personality and Social Psychology, vol. 51, no. 4, pp. 683, 1986.

[21] J. Gnoth, J. Bigné, L. Andreu, "Waiting time effects on the leisure experience and visitor emotions", Progress in Tourism Marketing, pp. 255,2006

[22] Van Riel, C.R. Allard, J. Semeijn, D. Ribbink, Y. Bomert-Peters, "Waiting for service at the checkout: Negative emotional responses, store image and overall satisfaction", Journal of Service Management, vol. 23, no. 2, pp. 144-69, 2012.

[23] J. Dawes, J. Rowley, "The waiting experience: towards service quality in the leisure industry", International journal of contemporary hospitality management, vol. 8, no. 1, pp. 16-21, 1996.

[24] L. Dubé-Rioux, B. Schmitt, F. Leclerc, "Consumers' reactions to waiting: when delays affect the perception of service quality", Advances in consumer research, vol. 16, no. 1, pp. 59-63, 1989.

[25] D. Maister, "The Psychology of Waiting Lines", The Service Encounter: Managing Employee/Consumer Interaction in Service Businesses, J. A. Czepiel, M. R. Solomon, and C. F. Surprenant, eds. Lexington, MA: Lexington Books, pp. 113-126, 1985.

[26] J. Baker, M. Cameron, "The Effects of the Service Environment on Affect and Consumer Perception of Waiting Time: An Integrative Review and Research Propositions", Journal of the Academy of Marketing Science, vol. 24, no. 4, pp. 338-349, 1996.

[27] S. Oakes, "Musical tempo and waiting perceptions", Psychology marketing, vol. 20, no. 8, pp. 685-705, 2003.

[28] R. F. Cope, R. Cope III, A. N. Bass, H. A. Syrdal, "Innovative knowledge management at disney: Human capital and queuing solutions for services”, Journal of Service Science, vol. 4, no. 1, 2011.

[29] R. Cope III, R. Cope, H. Davis, "Disney's Virtual Queues: A Strategic Opportunity To Co-Brand Services?", Journal of Business \& Economics Research (JBER), vol. 6, no. 10, 1998.
[30] Biege,http://goireland.about.com/od/travelingtoireland/qt/ryanair_priorit y_boarding.htm, 2012.

[31] D. Gavilán-Bouzas, J. García de Madariaga Miranda, “Esperamos porque es mejor o es mejor porque esperamos? un estudio exploratorio de la relación entre el tiempo de espera y el valor percibido". Universia Business Review, vol. 26, no. 22, pp. 56-73, 2009.

[32] M. Koo, A. Fishbach, "A Silver Lining of Standing in Line: Queuing Increases Value of Products", Journal of Marketing Research, vol. 47, no. 4, pp. 713-724, 2010.

[33] S. Gudergan, "Individual's choice behavior in waiting situations". Academy of Marketing Studies Journal, vol. 1, no. 1, pp. 2227, 1997.

[34] L. G. Debo, S. K. Veeraraghavan, S. K., "Models of Herding Behavior in Operations Management". Consumer-Driven Demand and Operations Management Models, pp. 81-112, 2009.

[35] R. Ahmadi, "Managing capacity and flow at theme parks", Operations research, vol. 45, no. 1, pp. 1-13, 1997.

[36] C. Heger, S. Offermans, J. Frens, "Waiting as part of the fun: Interactive gaming in theme park queues", Offermans SAM, Nagtzaam HA H.Proceedings of SIDER, vol. 9, pp. 52-55, 2009.

[37] D. Dickson, R. Ford, B. Laval, "Managing real and virtual waits in hospitality and service organizations", Cornell Hotel and Restaurant Administration Quarterly, vol. 46, no. 1, pp. 52-68, 2005.

[38] M. Sundström, L. Christine, G. Stavroula, "Tourist shopping motivation: Go with the flow or follow the plan". International Journal of Quality and Service Sciences, vol. 3, no. 2, pp. 211, 2011.

[39] L. Mann, "Queue culture - waiting line as a social system", American Journal of Sociology, vol. 75, no.3, pp. 340-354, 1969.

[40] F. N. Brady, "Lining up for star-wars tickets: Some ruminations on ethics and economics based on an internet study of behavior in queues”. Journal of Business Ethics, vol. 38, no.1-2, pp. 157-165, 2002.

[41] A. Rafaeli, G. Barron, K. Haber, "The Effects of Queue Structure on Attitudes", Journal of service research, vol. 5, no. 2, pp. 125-139, 2002.

[42] W. Li, "Impact of waiting time on tourists satisfaction in a theme park: An empirical investigation", Industrial Engineering and Engineering Management (IEEM), 2010 IEEE International Conference on, pp. 434, 2010.

[43] R. Hensley, J. Sulek "Customer satisfaction with waits in multi-stage services", Managing Service Quality, vol. 17, no. 2, pp. 152-173, 2007.

[44] C. Heo, S. Lee, "Application of revenue management practices to the theme park industry", International journal of hospitality management, vol. 28, no. 3, pp. 446-453, 2009.

[45] A. Matthew, A. MacLaren, K. O'Gorman, C. White, "Priority queues: Where social justice and equity collide", Tourism Management, vol. 33, no. 4, pp. 875-884, 2012.

[46] P. Pearce, "Towards the better management of tourist queues", Tourism management, vol. 10, no. 4, pp. 279-284, 1989.

[47] G. McClung, "Theme park selection: Factors influencing attendance", Tourism Management, vol. 12, no. 2, pp. 132-140, 1991.

[48] L. Álvarez, G. Mejía, "Simulation study of priority passes in a theme park in Colombia", Proceedings of the 2012 Industrial and Systems Engineering Research Conference G. Lim and J.W. Herrmann eds, 2012.

[49] T. Tone, K. Kohara, "A Study of the Effects of Congestion Information and a Priority Boarding Pass in a Theme Park with Multi-Agents", IEEJ Transactions on Electronics, Information and Systems, vol. 127, pp. 407415, 2007.

[50] Empire State Building Company L.L.C. http://www.esbnyc.com/local/es/observatory.asp. 2012.

[51] Roma Pass. http://www.romapass.it/p.aspx?l=en\&tid=33\&hi=queue. 2008 